\title{
Recovery of diesel-like fuel from waste palm oil by pyrolysis using a microwave heated bed of activated carbon
}

\begin{abstract}
Microwave pyrolysis using a well-mixed bed of activated carbon as both the microwave absorber and reaction bed was investigated for its potential to recover useful products from waste palm cooking oil - a cooking oil widely used in Asia. The carbon bed provided rapid heating $\left(\sim 18{ }^{\circ} \mathrm{C} / \mathrm{min}\right)$ and a localized reaction hot zone that thermally promoted extensive pyrolysis cracking of the waste oil at $450{ }^{\circ} \mathrm{C}$, leading to increased production of a biofuel product in a process taking less than $25 \mathrm{~min}$. It also created a reducing reaction environment that prevented the formation of undesirable oxidized compounds in the biofuel. The pyrolysis produced a biofuel product that is low in oxygen, free of sulphur, carboxylic acid and triglycerides, and which also contains light $\mathrm{C}_{10}-\mathrm{C}_{15}$ hydrocarbons and a high calorific value nearly comparable to diesel fuel, thus showing great potential to be used as fuel. This pyrolysis approach offers an attractive alternative to transesterification that avoids the use of solvents and catalysts, and the need to remove free fatty acids and glycerol from the hydrocarbon product. The pyrolysis apparatus operated with an electrical power input of $1.12 \mathrm{~kW}$ was capable of producing a biofuel with an energy content equivalent to about $3 \mathrm{~kW}$, showing a positive energy ratio of 2.7 and $\geq 73 \%$ recovery of the energy input to the system. The results show that the pyrolysis approach has huge potential as a technically and energetically viable means for the recovery of biofuels from the waste oil.
\end{abstract}

Keyword: Pyrolysis; Microwave pyrolysis; Waste cooking oil; Palm oil; Activated carbon 